\title{
A prevalence study of children with imprisoned fathers: annual and lifetime estimates
}

Susan Dennison, Anna Stewart and Kate Freiberg

\begin{abstract}
In Australia, data are not routinely collected on the parental status of prisoners, so there are no official nationwide figures and few State-based figures. The current study uses data collected in Queensland over a six-month period to estimate how many Queensland children, in one year and in their entire childhood, experience paternal imprisonment. Additional data were collected relating to the provision of care for the child prior to, and during, their father's imprisonment. Participants were 303 imprisoned fathers (51 per cent of Aboriginal and/or Torres Strait Islander origin) who reported a total of 753 children. Using these data and population statistics, it was estimated that 0.8 per cent of children in Queensland experienced paternal imprisonment in one year while approximately four per cent experience paternal imprisonment in their lifetime. Indigenous children were nine times more likely to experience paternal imprisonment in one year and four times more likely to experience paternal imprisonment in their lifetime compared to non-Indigenous children. Approximately half of the children (48 per cent) lived with their father prior to his imprisonment. Results are discussed in relation to whether children were living with their father as well as the possibility of pre-existing risks in children's lives that may subsequently interact with their father's imprisonment.
\end{abstract}

Keywords: children, families, prison, paternal incarceration, imprisonment 


\section{Introduction}

Criminological knowledge on the long-term effects of imprisonment on offenders is incomplete and only beginning to be examined in relation to the second-generation effects on children. In the last decade, there has been an increase in research addressing the question of whether parental imprisonment substantially adds to a young person's risk of offending and other poor developmental outcomes, or whether it has a limited effect in the presence of a high concentration of other risk factors (for example, Murray \& Farrington 2005, 2008; Foster \& Hagan 2007; Kinner et al. 2007; Besemer et al. 2011; Geller et al. 2012; see Murray 2010 for a review of the longitudinal research). A recent meta-analysis of 40 studies revealed that parental incarceration is associated with a higher risk of antisocial behaviour in children, but not with mental health problems, drug use or poor educational performance (Murray et al. 2012). New questions are also emerging regarding the processes that transmit risk to children. Similarly, it is important to consider whether parental imprisonment is sometimes a protective factor for children.

These are vital questions as imprisonment is a frequently used response to offending. Although the national imprisonment rate declined by two per cent in Australia between 2010 and 2011, it increased by one per cent between 2011 and 2012, when it stood at 168 prisoners per 100,000 adult population (ABS 2012a). The number of Aboriginal and Torres Strait Islander prisoners increased by four per cent during 2011 and 2012 and the total Australian prisoner population increased by 31 per cent between 2002 and 2012 (ABS 2012a). Most recently, Sampson (2011: 820) has argued that 'it is incumbent on criminologists to think in terms of the social ledger of incarceration's effects'.

At a more basic level, there is surprisingly little knowledge in Australia regarding the extent to which Australian children are affected by parental (maternal and paternal) imprisonment. Data are not routinely collected on the parental status of prisoners and therefore there are no nationwide figures. A similar problem exists in the United States, where it has been estimated that in 2007, 52 per cent of State prisoners and 63 per cent of federal prisoners were parents of minor children (Maruschak et al. 2010: 35). Furthermore, 1.7 million children (or one in every 43 children) were estimated to have a parent in State or federal prison in 2007 (Maruschak et al. 2010: 37). Approximately 91 per cent of these children experienced paternal imprisonment, rather than maternal imprisonment.

A study using data collected from the 2001 New South Wales Inmate Health Survey, consisting of a cross-section of 914 inmates randomly selected from 29 correctional facilities, assessed the number of children experiencing parental imprisonment (Quilty 2003; Quilty et al. 2004). Approximately 335 fathers and 83 mothers were included in the survey (sample sizes calculated from percentages reported). Preliminary estimates indicated that almost one in 20 children in New South Wales have experienced parental imprisonment in their lifetime (Quilty et al. 2004: 342). This would amount to around 172,000 children, based on population estimates by the Australian Institute of Health 
and Welfare (2005). The proportion is even higher for Indigenous children, such that approximately one in five NSW children have experienced parental imprisonment in their lifetime (Quilty et al. 2004: 342). National estimates drawn from the NSW data show that one in 200 children ( 0.5 per cent), aged 15 years or younger, have a father in prison (Quilty 2003).

The high rates of Indigenous children's experience with parental imprisonment are associated with the overrepresentation of Aboriginal and Torres Strait Islander peoples in the court system (ABS 2012b) and in correctional facilities. According to the 2011 Census, Indigenous people comprise 2.5 per cent of the Australian population, 2.5 per cent of the NSW population and 3.6 per cent of the population in Queensland (ABS 2012c). Of Indigenous Australians, 90 per cent are of Aboriginal origin, 6 per cent of Torres Strait Islander origin, and 4 per cent identify as both Aboriginal and Torres Strait Islander origin (ABS 2012c). Despite accounting for a small percentage of the population, Indigenous people comprise approximately 27 per cent of the Australian prison population. This rate is 15 times higher than for non-Indigenous prisoners (ABS 2012a). The percentage of Indigenous prisoners was slightly higher in Queensland (29.7 per cent or 1,663 persons) (ABS 2012a). Further, Indigenous prisoners are more likely to have prior adult imprisonment (74 per cent) than non-Indigenous prisoners (48 per cent) (ABS 2012a). Based on these figures alone, it is apparent that, proportionally, Indigenous children are more likely than non-Indigenous children to experience the imprisonment of a parent as well as repeat parental imprisonment.

The focus of the current study is on fathers, as there is little known about the extent of paternal imprisonment or who children reside with prior to and during their father's prison term. This may be due to an assumption that most children remain with their mothers, so that the father's imprisonment has minimal impact on the family. However, research in the United States and United Kingdom has revealed that families of prisoners may experience serious emotional, financial and social consequences (Johnston 1995; Walker \& McCarthy 2005; Foster \& Hagan 2007; Geller et al. 2009; Schwartz-Soicher et al. 2011). Furthermore, if the status of the male prisoner as a father is ignored, this may affect the father's ability to maintain relationships with their children and affect the quality of their visits. It may also affect the level of support and services that are provided for their families in the community.

Using data from a nationally representative survey of prisoners conducted in 1997 and 2004 by the Bureau of Justice Statistics (BJS) in the United States, Maruschak and colleagues (2010) reported on key findings pertaining to imprisoned parents and their children. It was estimated that only 48 per cent of parents in state prison were living with at least one of their children in the month before arrest or just prior to their imprisonment (Glaze \& Maruschak 2008, Maruschak et al. 2010: 40). This figure was higher for mothers than for fathers. These are relevant figures because recent research in the United States using a large sample of 3,000 children revealed a significant positive 
relationship between paternal incarceration and increased child aggression. The relationship was stronger if the child had been living with the father prior to his imprisonment (Geller et al. 2012: 66).

According to the BJS survey, only one quarter of fathers versus three quarters of mothers reported providing the primary care to their children prior to their imprisonment. Furthermore, almost 90 per cent of State imprisoned fathers reported having at least one child in the care of their biological mother, whereas State imprisoned mothers most commonly (42 per cent) reported that the child's grandmother was the current caregiver of the child. Less than half (42 per cent) of parents in State prison received a personal visit from their child, with letter writing being the most common form of contact (70 per cent). Weekly contact with children declined with longer time served, from 46 per cent for those who had served less than a year, to 41 per cent for those who had served between 12-59 months, down to 34 per cent for those who had served more than 60 months in prison (Maruschak et al. 2010: 43). Findings such as these reveal that any approach to understanding whether and how paternal imprisonment has a detrimental or protective effect on children will be complex and require an understanding of the variations in relationships that exist between children and their imprisoned father.

With respect to imprisoned fathers and the Australian context, three key questions emerge from the NSW estimates. First, how generalisable are these estimates beyond NSW? That is, are similar proportions of children in other Australian States experiencing paternal imprisonment? Second, what degree of contact did these children have with their father prior to his imprisonment? If children who lived with their father prior to his imprisonment are at heightened risk of displaying increased aggression (Geller et al. 2012: 66), then it is important to determine to how many children this risk might apply. Third, who is the primary caregiver of the children while their father is in prison? These are fairly basic questions, yet it is essential to address them if we are going to correctly assess the potential scope of the problem and direct resources to prevent second-generation effects of paternal imprisonment. These questions are yet to be systematically addressed in Australia.

The current study used data collected in Queensland over a six-month period in 2008 and 2009 to estimate how many children in Queensland, in one year and in their entire childhood, experienced the imprisonment of their father. The purpose of the study was to examine the generalisability of Quilty's (2004) NSW findings and to examine the living and care arrangements of children with a father in prison. The specific questions addressed were:

1. How many children in Queensland experience paternal imprisonment in one year and across their childhood?

2. What degree of contact did these children have with their father prior to his imprisonment?

3. Who is the primary caregiver of the children while their father is in prison? 


\section{Method}

\section{Sample Selection}

Eligible participants were drawn from all new intakes of male prisoners over a six-month period (from October 2008 to March 2009) across the five Queensland reception prisons (Brisbane Correctional Centre, Maryborough Correctional Centre, Townsville Correctional Centre, Lotus Glen Correctional Centre, Capricornia Correctional Centre). A total of 2,962 admissions were made during this data collection period. Of these new intakes, 36 per cent $(n=1,055)$ of men were approached to participate in the study. We aimed to invite as many new intakes as possible to participate in the study. At the point of approaching potential participants, their parental status was not known. Whether men were approached was dependent upon the workload of the correctional staff member at the time. As Brisbane Correctional Centre (BCC) is the reception and remand prison for South East Queensland, the most densely populated part of the State, the volume of intake assessment to be conducted is large. As a consequence of time constraints on staff, data were collected for a six-month period in all prisons except BCC, where data were only collected for four months (October - January). Therefore, there was a period of two months during which potential participants were not approached at BCC. Further, during the first four months the rate of approaching potential participants at this Centre was low. While we do not know the parental status of those who were not approached, there is no reason to believe that it would have been different to those participants who were approached, since there was no systematic bias in the recruitment method.

Of men approached to participate, 381 were not eligible as they indicated they did not have children aged 0-17 years. Eighty-three men were not ultimately invited to participate as the prison psychologist or counsellor deemed it inappropriate given their current mental or physical state; their parental status is unknown. Of the remaining 591 potentially eligible men, 303 men were fathers and agreed to participate in the study (51 per cent consent rate). The parental status of those who declined to participate without giving a reason $(n=288)$ is not known.

\section{Participants}

The ages of the 303 participants ranged from 18 to 58 years $(M=32.23$, $S D=8.59)$. Just over half of the men identified themselves as Indigenous (51.2 per cent). For sentenced participants (66.7 per cent), current sentence lengths averaged 19.6 months $(S D=22.83)$ with a median of 12 months. In Queensland in the period 2010-2011 the mean and median sentence lengths in the Higher Courts were 20 months and 12 months respectively, and in the Magistrate's Court the mean was approximately six months and the median four months (ABS 2012a). Given that more defendants are sentenced to custody in the Magistrates Court than in the Higher Courts, the sample data appear to disproportionately represent prisoners with longer sentences. Importantly, however, there was no significant difference between the average sentence 
lengths of participants in the study and all the other admissions over the six-month period. One possible explanation for the relatively high means in both groups is that our sentence length data do not include the remand prisoners in our study. Remand prisoners who have been sentenced to shorter terms through the Magistrates Court may be released immediately if their period on remand meets their sentence. They do not enter the correctional system as a sentenced prisoner. Therefore our correctional system data may contain fewer shorter sentences compared to court data.

Men reported having between one and nine children, with the most frequent being one child (39 per cent), followed by two children ( 26 per cent), three children (13 per cent), four children (10 per cent), five children (six per cent) and six to nine children (six per cent). Non-Indigenous men had an average of 2.29 children $(S D=1.60)$, which was significantly fewer than those of the Indigenous men $(M=2.74, S D=1.66), t(294)=-2.36, p<.05)$.

\section{Representativeness of sample}

It was not possible to compare how representative the fathers in this study were to all fathers in prison with children under 18 years, since the parental status of prisoners is not recorded in official administrative data. It is possible that our sample differed from the wider group of imprisoned fathers who were not approached or declined to participate in terms of the quality of their relationships and contact with children prior to imprisonment. Therefore, in order to attempt to assess the representativeness of the sample, the 303 participants were compared on a range of variables to all other admissions during the six-month data collection period. The two groups did not differ significantly with respect to age, highest level of education, offence type, total number of current offences, total sentence length, total number of previous offences for which they were sentenced, total number of previous episodes in prison, and the cumulative total of episode lengths in prison (in months). They did, however, differ significantly on three variables. The men who consented were significantly more likely to be married or in a defacto relationship $(41.2$ per cent) than the other men $(28.3$ per cent $)(\chi 2(6, N=3001)=47.73, p<.001$, Cramer's $V=.126)$. While there was a significant difference in the number of children that the participant sample reported according to their marital status $(F(4,293)=4.04, p<.01)$, post hoc analyses using Tukey $\mathrm{B}^{1}$ revealed that the only significant difference was between men who were never married $(M=2.15$, $S D=156)$ and divorced men $(M=3.64, S D=1.86)$. Since there was no significant difference between the number of children men who were married or in defacto relationships had and the number other groups had, no adjustments were made in subsequent analyses for the marital status of prisoners.

As noted earlier, significantly more participants were Indigenous men (51.2 per cent) than in the remaining admissions (31.8 per cent) $(\chi 2(1, N=2966)=44.67$, $p<.001$, Cramer's V=.123). In Queensland, Indigenous prisoners comprise approximately 30 per cent of the prison population (ABS 2012a). The high 
number of Indigenous men in our study is likely a consequence of the better response rate in the Central and Northern Queensland prisons, which have a higher proportion of Indigenous prisoners than in South East Queensland. As described above, in the participant sample Indigenous men had significantly more children than non-Indigenous men. This is addressed in the analyses below by providing separate annual and lifetime estimates for Indigenous and non-Indigenous prisoners and their children. Also, significantly fewer participants had been sentenced (66.7 per cent) than in the remaining admissions (77.4 per cent) $(\chi 2(1, N=3005)=17.18, p<.001)$, Cramer's $V=.076$. There was no significant difference in the number of children of prisoners according to whether the prisoner was sentenced $(M=2.41, S D=1.54)$ versus on remand $(M=2.71, S D=1.82)(t(300)=-1.47, p=.142)$, therefore no adjustments were made in the subsequent analyses for sentence status.

\section{Materials}

An 11-item survey, that took participants 10-15 minutes to complete, was used to collect data for this study. The first three items asked about the participants' sentence status (sentenced, on remand, or sentenced with further remands), their age (in years) and how many children they had under the age of 18 years. Items 4-10 were completed separately for each child of the participant. The child's birth date was recorded (if known), otherwise the current age of the child was noted (item 4). Item 5 recorded whether the child was of Aboriginal (yes, no) or Torres Strait Islander (yes, no) descent. Item 6 recorded the child's gender (male, female) and item 7 recorded whether the child was the biological child or step-child of the participant. If the participant indicated it was their step-child, they were requested to indicate how long they had been the child's step-parent prior to their imprisonment. An 'other' relationship option was also provided to allow for kinship relationships to be recognised for Indigenous men. They were asked to describe that relationship if 'other' was selected.

Item 8 recorded whether the father was living with the child prior to their imprisonment (yes, no). If the child was not living with them, participants were requested to indicate whether they had limited custody, joint custody, or no custody rights for that child. This item also recorded how frequently the men had visitation arrangements with the child (every day, weekends only, weekly, fortnightly, monthly or other). Item 9 recorded the primary caregiver of the child during the participant's imprisonment (biological mother, step-mother, maternal grandparents, paternal grandparents, child's aunt or uncle, other relatives, Child Safety Services [such as foster carers], other). Item 10 recorded whether the participant expected to be living with the child or have visitation post-release (yes, child living with them permanently; visitation rights; not living with them and no visitation rights). The final item asked men where they were living prior to their imprisonment (own home owned outright, own home with mortgage/ rent-buy scheme, private rental, friends/relatives in long-term stay, friends/ relatives in temporary stay or uncertain length, government rental, caravan park, hostel/boarding house, motel/hotel, no fixed address [and length], other). 
The Correctional Centre in which the participant was housed was recorded. Participants were requested to provide their Individual Offender Management System Identification (IOMS ID) and to give permission for the researchers to match their responses to other IOMS data held by Queensland Correctional Services (QCS). Data obtained from IOMS related to demographic information, current imprisonment and offence details and previous criminal history. The demographic information included the participant's date of birth, ethnicity, marital status and highest level of education obtained. Current imprisonment details included the participant's offences for which they were convicted, episode length (total length rather than length for individual offences), episode start date, whether the episode had been completed at the time of data request (yes, no), and episode completion date (if episode completed). Previous criminal history details included offences that resulted in a sentence (sorted by the date of previous episodes of imprisonment, if more than one), total episode length (for each previous episode) and the start and end dates of each episode of imprisonment.

\section{Procedure}

A psychologist or counsellor administered the survey during their initial assessment of the prisoner, upon his receipt into the prison. Following discussion with QCS it was decided that this would be the most effective method to ensure that as many eligible men as possible would be approached to participate in the research, while maintaining security in the prison and ensuring that the men's mental health would be considered during the process. Every prisoner received into the prison undergoes such an assessment to determine their requirements while in prison and their security status. During this assessment, if deemed appropriate and with time permitting, the staff member would introduce the research project to the individual, emphasise that their participation was voluntary, and indicate that the project was being conducted by Griffith University in partnership with the QCS, the Department of Communities and the Catholic Prison Ministry. A full information sheet was provided to participants, which staff members read aloud if there were any literacy problems. The staff member then recorded whether the individual consented to participate, was not eligible (no children under 18 years), declined to participate, or was not appropriate to approach due to their current state. IOMS IDs were recorded for all individuals, regardless of whether they participated in the research. If the participant agreed to participate, the staff member administered the survey by reading each question aloud and marking responses. This aimed to overcome any potential problems with literacy and avoided missing data.

Prior to the implementation of the survey, the first author discussed the project with the psychologists and counsellors who would be responsible for the data collection in the prisons. The discussion took place either in person (Brisbane, Townsville) or via teleconference (Lotus Glen, Capricornia, Maryborough). The purpose of these discussions was to discuss the aim of the research and the staff's important contribution to it, and to ensure that all questions on the survey were clear. Once this process had been completed, the survey was trialled at Brisbane Correctional Centre for one week to assess whether the recruitment 
protocol was effective and whether there were any difficulties with the survey. Some minor revisions were made to the survey as a result. As Brisbane Correctional Centre is the main reception prison for South East Queensland, the number of men being processed through the centre on a daily basis is large. The staff conducting their intake assessments indicated that it was difficult to approach each eligible participant given time constraints. Alternative recruitment processes were considered, but none were viable, given security and movement issues within the prison. Despite these concerns, staff members were enthusiastic about the project and so the project commenced with the original protocol.

As already noted, data were collected for a six-month period in all prisons except at the Brisbane Correctional Centre, where data were only collected for four months. Consent indication forms and completed surveys were returned to the head office of QCS monthly, from where they were collected by Griffith University researchers. A senior research assistant maintained weekly contact with staff at each prison and posted additional research materials when required. Once the data collection period was completed, a request for additional data (demographic, current offence, criminal history) was sent to QCS with the IOMS IDs of all men who were approached to participate. The data were then matched with the survey data using IOMS IDs. The IOMS IDs were then replaced with unique identifiers. The project received ethical clearance from Griffith University's Higher Research Ethics Committee (LEJ/05/08/HREC).

\section{Statistical analysis}

In the analysis three estimates were calculated: (1) estimates of the number of children in Queensland who experienced the imprisonment of their father in one year (July 2008 to June 2009), and (2) estimates of the number of Queensland children who experience paternal imprisonment during their childhood (that is, 0-17 years of age) according to a) the average number of children of fathers imprisoned for the first time, and b) the average number of children of fathers in prison. The procedure for calculating these estimates and the assumptions underpinning the data are described below. Analyses were calculated using SPSS for Windows Version 21. These estimates are based on count data (number of children) that are not normally distributed. Therefore 95 per cent Confidence Intervals for estimates were calculated using Poisson confidence intervals. Poisson rate confidence intervals were calculated by employing the relationship between the Poisson and chi-square distributions (Ulm 1990).

\section{Estimate 1: Estimates for 2008-2009}

The data collected over the six-month period were used to estimate how many children in Queensland were likely to have experienced a father going to prison within the 12-month period of 1 July 2008 and 30 June 2009. The estimates were calculated in a series of four steps:

- Step 1 - The number of imprisoned fathers in 2008-2009 was calculated by multiplying the number of men in prison in Queensland in that year by the percentage of fathers in our study. 
- Step 2 - The number of children with an imprisoned father was then estimated by multiplying the number of fathers calculated in Step 1 by the average number of children per father in our study.

- Step 3 - We divided the number of children with an imprisoned father (estimated in Step 2) by the population of children aged 0-17 years in Queensland in 2008. This provided an estimate of the percentage of children who experienced paternal imprisonment in the year 2008-09.

- Step 4 - Estimates were then calculated separately according to the Indigenous status of the fathers using the same steps above.

Key assumptions made in calculating these estimates were:

1. That there were no differences between the parental statuses of incarcerated men who did participate in the study and those who did not participate in the study.

2. That the self-report measures of parental status and number of children are accurate.

In addition to the data obtained in the current study, data from official sources were also required to conduct estimates. These were:

1. The number of men imprisoned in Queensland between July 2008 and June 2009 ( $N=7,808 ; 5,700$ non-Indigenous men; 2,108 Indigenous men) (figures provided to the authors by Queensland Corrective Services).

2. The number of children aged 0-17 years in Queensland in 2008 by Indigenous status. The most recent published population data for children in Queensland was for 2007 and estimates of the number of Indigenous children in Queensland were available for 2006 ( $N=1,020,421$; 954,937 non-Indigenous children; 65,484 Indigenous children) (ABS 2008). Given that 2008 data were used in the numerator (percentage of imprisoned men with children) the population of non-Indigenous children in 2007 was adjusted for one year to create 2008 figures, using the average annual growth rate in the population (2006-2011) of 2.3 per cent (ABS 2012d). For the Indigenous population, the average annual growth rate was estimated to be 2.6 per cent (1991-2006), while the projected annual growth rate for 2006-2021 is 2.7 per cent (ABS 2009). The midpoint of 2.65 per cent was used to estimate the 2008 population of Indigenous children from the 2006 data. These population adjustments resulted in 976,901 non-Indigenous children and 68,955 Indigenous children (estimated $N=1,045,856$ children aged 0-17 years in Queensland in 2008).

\section{Estimates $2 \mathrm{a}$ and $2 \mathrm{~b}$ : lifetime estimates}

Estimates of the number of Queensland children who experience paternal imprisonment during their childhood (0-17 years of age) were calculated according to the average number of children of fathers imprisoned for the first time (Estimate 2a). The estimates were calculated in a series of five steps: 
- Step 1 - The number of imprisoned fathers in prison for the first time in 2008-2009 was calculated by multiplying the number of men in prison in Queensland in that year by the percentage of fathers who were in prison for the first time in our study.

- Step 2 - The number of children with a first-time imprisoned father was then estimated by multiplying the number of fathers calculated in Step 1 by the average number of children per father (for first-time imprisonment) in our study.

- Step 3 - The total number of children aged 0-17 years who experienced first-time paternal imprisonment was then calculated in the following way: once the number of children in Queensland in 2008 who experienced paternal imprisonment was estimated (described in the 2008/09 estimates), this figure was then adjusted for each year from 2007 back to 1991 according to the annual rate change in the Queensland population between 1991 and 2008. This annual rate change was manually calculated from annual Queensland population figures (ABS 2008). Annual figures were not available for the Indigenous population in Queensland for the years 1984, 1985, 1987-1990 and 1997-1999 inclusive. The average Indigenous annual rate change of 2.46 (over the 18 years) was applied in these years. Once the number of children who experienced first-time paternal imprisonment was calculated for each of the 17 years, these figures were then summed.

- Step 4 - We divided the number of children aged 0-17 years with a first-time imprisoned father (estimated in Step 3) by the population of children aged 0-17 years in Queensland in 2008. This provided an estimate of the percentage of children in Queensland who experienced paternal imprisonment by the age of 17 years (between 1991 and 2008).

- Step 5 - Estimates were then calculated separately according to the Indigenous status of the fathers using the same steps above.

Next, estimates of the number of Queensland children who experience paternal imprisonment during their childhood were calculated according to the average number of children of fathers in prison (Estimate $2 \mathrm{~b}$ ). The same five steps as those described above were used, with the exception that the average number of children per father was used in Step 2 instead of the average number of children of fathers imprisoned for the first time.

Assumptions made in calculating the analyses were the same as above with the addition of two further assumptions:

1. That the percentage of fathers in prison remains stable over time. We have no information either to confirm or contradict the validity of this assumption. 
2. That prisoner numbers remain stable over time. This assumption was made for ease of calculating estimates. We do, however, know that prisoner numbers have increased over the past decade (ABS 2012a). A sensitivity analysis was conducted to account for increases in prisoner numbers over the past 18 years.

An additional variable not used in the first estimate was:

1. The percentage of men imprisoned for the first time between July 2008 and June 2009 ( $N=37.6$ per cent; 49 per cent [ $n=2793$ ] non-Indigenous men, 25 per cent $[n=527]$ Indigenous men) (figures provided to the authors by Queensland Corrective Services).

\section{Results}

\section{Summary statistics}

Participants reported having a total of 753 children between them $(54.2$ per cent males, 45.8 per cent females, $n=30$ missing). The ages of their children ranged from two days old to 17 years $(M=7.08, S D=4.86)$. The majority of men reported being the biological fathers of the child. In the case of non-Indigenous men, 80 per cent were the biological father and 20 per cent were the step-father of the child. For Indigenous men, 93 per cent were the biological father, six per cent were the stepfather, and one per cent reported another kinship relationship with the child (such as an uncle) that carried parental-like responsibilities. Of the children, 63.2 per cent were Aboriginal or Torres Strait Islander or both, with the remaining 36.8 per cent being non-Indigenous.

Participants' reports show that 48.4 per cent of the children lived with their father prior to his imprisonment (52 per cent non-Indigenous children, 47 per cent Indigenous children). When asked whether their child/ren would live with them after imprisonment or whether they would have visitation rights, fathers reported that 45.2 per cent of the children would be living with them permanently and they would have visitation rights with 39.3 per cent of the children, while 14.3 per cent of the children would not be living with or have visitation with their father, and for 1.1 per cent of the children their living status was uncertain. According to fathers, of children who were living with them prior to imprisonment $(n=348), 87.6$ per cent were expected to be living with their father after his release, while 10.3 per cent were expected to visit their father and two per cent of children were expected to have no further contact with their father.

Primary caregiver arrangements for the child while the father was imprisoned were examined. Table 1 reveals that the biological mother is typically the primary caregiver for the child while the father is in prison. This does not differ significantly according to the Indigenous status of the child $(\chi 2(4, N=715)=4.75$, $p<.314$, Cramer's V=.082). However, as depicted in Table 2, the primary caregiver does differ significantly according to whether the child was living with the father prior to his imprisonment $(\chi 2(4, N=725)=14.48, p<.001$, Cramer's 
$V=.141$ ). Children were less likely to be living with their biological mother and more likely to be in the care of the Child Safety Services if they had not been living with their father prior to imprisonment.

Table 1: Primary caregiver while father is in prison by Indigenous status

\begin{tabular}{lccc}
\hline & $\begin{array}{c}\text { Non-Indigenous } \\
\text { children } \\
\mathrm{N}(\%)\end{array}$ & $\begin{array}{c}\text { Indigenous } \\
\text { children } \\
\mathrm{N}(\%)\end{array}$ & $\mathrm{N}(\%)$ \\
\hline Biological mother & $227(85.7)$ & $367(81.6)$ & $594(83.1)$ \\
Grandparents & $9(3.4)$ & $27(6.0)$ & $36(5.0)$ \\
Other relatives & $11(4.2)$ & $30(6.7)$ & $41(5.7)$ \\
Child Safety Services & $13(4.9)$ & $18(4.0)$ & $31(4.3)$ \\
Other & $5(1.9)$ & $8(1.8)$ & $13(1.8)$ \\
\hline Total & $265(100.0)$ & $450(100.0)$ & $715(100.0)$ \\
\hline
\end{tabular}

Table 2: Primary caregiver arrangements according to whether the child lived with the father prior to his imprisonment

\begin{tabular}{lccc}
\hline & $\begin{array}{c}\text { Not living with father } \\
\text { N (\%) }\end{array}$ & $\begin{array}{c}\text { Living with father } \\
\text { N (\%) }\end{array}$ & $\begin{array}{c}\text { Total } \\
\text { N (\%) }\end{array}$ \\
\hline Biological mother & $293(78.3)$ & $309(88.0)$ & $602(83.0)$ \\
Grandparents & $23(6.1)$ & $13(3.7)$ & $36(5.0)$ \\
Other relatives & $26(7.0)$ & $16(4.6)$ & $42(5.8)$ \\
Child Safety Services & $24(6.4)$ & $7(2.0)$ & $31(4.3)$ \\
Other & $8(2.1)$ & $6(1.7)$ & $14(1.9)$ \\
\hline Total & $374(100.0)$ & $351(100.0)$ & $725(100.0)$
\end{tabular}

In order to examine stability of accommodation and extent of homelessness, the type of accommodation that fathers were living in prior to their imprisonment was examined separately according to whether the father had his children living with him. Table 3 shows that men with less stable housing arrangements were significantly less likely to have their children living with them prior to their imprisonment $(\chi 2(10, N=299)=43.92, p<.001$, Cramer's $V=.383)$. Fewer than half of the men owned or were purchasing their own home, or were living in private rental accommodation.

\section{Experience with paternal imprisonment: estimates for 2008-2009}

The data collected over the six-month period were used to estimate how many children in Queensland were likely to have experienced the imprisonment of their father between 1 July 2008 and 30 June 2009. Results are presented in Table 4. In these 12 months, 8,033 Queensland children were estimated to have experienced the imprisonment of their father. Indigenous children were nine times more likely than non-Indigenous children to have experienced paternal imprisonment (4.44 per cent versus 0.49 per cent respectively). 
Table 3: Type of housing in relation to whether the child lived with the father prior to his imprisonment

\begin{tabular}{lccc}
\hline Type of accommodation & Not living with father & Living with father & Total \\
& $\mathrm{N}(\%)$ & $7(5.1)$ & $12(4.0)$ \\
\hline Own home (own outright) & $5(3.1)$ & $20(14.5)$ & $29(9.7)$ \\
Own home & $9(5.6)$ & $57(41.3)$ & $92(30.8)$ \\
(mortgage/rent-buy scheme) & $35(21.7)$ & $29(21.0)$ & $88(29.4)$ \\
Private rental & $59(36.6)$ & $6(4.3)$ & $25(8.4)$ \\
Friends/relatives (long-term stay) & $19(11.8)$ & $15(10.9)$ & $24(8.0)$ \\
Friends/relatives & $9(5.6)$ & $0(0.0)$ & $6(2.0)$ \\
(temporary, uncertain) & $6(3.7)$ & $0(0.0)$ & $2(0.7)$ \\
Government rental & $2(1.2)$ & $0(0.0)$ & $4(1.3)$ \\
Caravan park & $4(2.5)$ & $1(0.7)$ & $7(2.3)$ \\
Hostel/boarding house & $6(3.7)$ & $3(2.2)$ & $10(3.3)$ \\
Motel/hotel & $7(4.3)$ & $138(100.0)$ & $299(100.0)$ \\
No fixed address & $161(100.0)$ & & \\
Other & & & \\
\hline Total & & & \\
\hline
\end{tabular}

Table 4: Estimates of the number of Queensland children who experienced paternal imprisonment in 2008-2009

\begin{tabular}{|c|c|c|c|c|c|c|}
\hline & $\begin{array}{c}\text { Non- } \\
\text { Indigenous } \\
\text { fathers }\end{array}$ & $\begin{array}{l}95 \% \mathrm{Cls} \\
\text { (lower; } \\
\text { upper) }\end{array}$ & $\begin{array}{l}\text { Indigenous } \\
\text { fathers }\end{array}$ & $\begin{array}{l}95 \% \mathrm{Cls} \\
\text { (lower; } \\
\text { upper) }\end{array}$ & Total & $\begin{array}{l}95 \% \mathrm{Cls} \\
\text { (lower; } \\
\text { upper) }\end{array}$ \\
\hline No. of fathers in sample & 144 & & 152 & & 303 & \\
\hline No. of children in sample & 330 & & 416 & & 753 & \\
\hline Children per adult (lamda) & 2.29 & $(2.05 ; 2.55)$ & 2.74 & $(2.48 ; 3.01)$ & 2.49 & $(2.31 ; 2.67)$ \\
\hline No. of fathers $2008-09 a$ & 2109 & & 1117 & & 3226 & \\
\hline $\begin{array}{l}\text { No. of children with } \\
\text { imprisoned father }\end{array}$ & 4829 & $(4345 ; 5378)$ & 3061 & $(2770 ; 3362)$ & 8033 & $(7452 ; 8613)$ \\
\hline $\begin{array}{l}\text { Population of children } \\
0-17 \text { years in } 2008\end{array}$ & 976,901 & & 68,955 & & $1,045,856$ & \\
\hline $\begin{array}{l}\text { \% experienced paternal } \\
\text { imprisonment }\end{array}$ & $0.49 \%$ & $\begin{array}{l}(0.44 \% ; \\
0.55 \%)\end{array}$ & $4.44 \%$ & $\begin{array}{l}(4.02 \% ; \\
4.88 \%)\end{array}$ & $0.77 \%$ & $\begin{array}{l}(0.71 \% ; \\
0.82 \%)\end{array}$ \\
\hline
\end{tabular}

Note. Six participants (fathers) missing Indigenous status. aThis figure was based on $37 \%$ non-Indigenous men having children and $53 \%$ Indigenous men having children as obtained in this study.

\section{Experience with paternal imprisonment: lifetime estimates}

The data from the annual estimate above were then used to estimate children's lifetime (entire childhood 0-17 years) experience of paternal imprisonment. Two analyses were conducted. The first was a more conservative estimate of children's lifetime experience of paternal imprisonment, basing calculations on the average number of children that men have when imprisoned for the first time. The results of this analysis are presented in Table 5. Using this conservative approach, approximately 40,406 Queensland children (3.85 per cent of children aged 0-17 years in 2008) were estimated to experience the imprisonment of their father by the time they were 17 years old. Indigenous children were almost four times more likely to experience paternal imprisonment than non-Indigenous children (12.51 per cent versus 3.25 per cent respectively). 
Table 5: Estimates of Queensland children's lifetime experiences of paternal imprisonment according to average number of children when father is imprisoned for the first time

\begin{tabular}{|c|c|c|c|c|c|c|}
\hline & $\begin{array}{c}\text { Non-Indigenous } \\
\text { father }\end{array}$ & $\begin{array}{c}95 \% \mathrm{Cls} \\
\text { (lower; upper) }\end{array}$ & $\begin{array}{l}\text { Indigenous } \\
\text { father }\end{array}$ & $\begin{array}{c}95 \% \text { Cls } \\
\text { (lower; upper) }\end{array}$ & Total & $\begin{array}{c}95 \% \mathrm{Cls} \\
\text { (lower; upper) }\end{array}$ \\
\hline $\begin{array}{l}\text { No. of fathers in sample } \\
\text { (first time in prison) }\end{array}$ & 70 & & 37 & & 107 & \\
\hline $\begin{array}{l}\text { No. of children in sample } \\
\text { (first time father in prison) }\end{array}$ & 146 & & 78 & & 224 & \\
\hline $\begin{array}{l}\text { Average number of children } \\
\text { per father (for first time } \\
\text { imprisonment) }\end{array}$ & 2.08 & $(1.76 ; 2.45)$ & 2.11 & $(1.67 ; 2.63)$ & 2.09 & $(1.84 ; 2.38)$ \\
\hline $\begin{array}{l}\text { No. of men in prison first time } \\
\text { with children 2008-09 }\end{array}$ & 1,033 & & 279 & & 1,312 & \\
\hline $\begin{array}{l}\text { No. of children first time paternal } \\
\text { imprisonment 2008-09 }\end{array}$ & 2,148 & $(1,818 ; 2,531)$ & 589 & $(466 ; 734)$ & 2,737 & $(2,414 ; 3,123)$ \\
\hline $\begin{array}{l}\text { Total number of children } \\
0-17 \text { years (between 1991-2008) } \\
\text { who experienced paternal } \\
\text { imprisonment }\end{array}$ & 31,781 & $(26.898 ; 37,448)$ & 8,625 & $(6,824 ; 10,763)$ & 40,406 & $(35,638 ; 46,105)$ \\
\hline $\begin{array}{l}\text { Population of children } \\
0-17 \text { years in } 2008\end{array}$ & 976,901 & & 68,955 & & $1,045,856$ & \\
\hline Percent of children in QLD & $3.25 \%$ & $(2.75 \% ; 3.83 \%)$ & $12.51 \%$ & $(9.90 \% ; 15.61 \%)$ & $3.86 \%$ & $(3.41 \% ; 4.41 \%)$ \\
\hline
\end{tabular}

Given that approximately two-thirds of our sample had been imprisoned previously in an adult prison, which is consistent with national figures (ABS 2012a), a second analysis was conducted using the average number of children of all fathers in prison in Queensland. This higher average was still only calculated according to the number of fathers in prison for the first time so as not to inflate the estimates. At the same time, it allowed for the possibility that many of these men will be imprisoned again and are also likely to have more children. This analysis is presented in Table 6. The first and second lifetime analyses therefore provide a range within which to consider children's lifetime experience of paternal imprisonment. In this second analysis, approximately 48,748 children (4.66 per cent of children aged 0-17 years in 2008) were estimated to have experienced the imprisonment of their father by the time they were 17 years old. Again, Indigenous children were four times more likely than non-Indigenous children to experience paternal imprisonment in their lifetime (16.28 per cent versus 3.84 per cent respectively).

A sensitivity analysis was conducted to assess the stability of the lifetime estimates. The results were recalculated using data from Table 6 based on the premise that the prison population had increased by 10 per cent each year since 1991, rather than being the annual population of 8033 male prisoners from which the estimates were calculated. Therefore a 10 per cent increase in prisoner numbers was deducted from each annual estimate. Results revealed that even with such a cautious approach, the estimates were very stable, with 4.2 per cent of children in Queensland experiencing paternal imprisonment in their lifetime using this approach. 
Table 6. Estimates of Queensland children's lifetime experiences of paternal imprisonment according to average number of children of fathers in prison

\begin{tabular}{|c|c|c|c|c|c|c|}
\hline & $\begin{array}{c}\text { Non-Indigenous } \\
\text { father }\end{array}$ & $\begin{array}{c}95 \% \mathrm{Cls} \\
\text { (lower; upper) }\end{array}$ & $\begin{array}{l}\text { Indigenous } \\
\text { father }\end{array}$ & $\begin{array}{c}95 \% \text { Cls } \\
\text { (lower; upper) }\end{array}$ & Total & $\begin{array}{c}95 \% \mathrm{Cls} \\
\text { (lower; upper) }\end{array}$ \\
\hline No. of fathers in sample & 144 & & 152 & & 303 & \\
\hline No. of children in sample & 330 & & 416 & & 753 & \\
\hline $\begin{array}{l}\text { Average number of children } \\
\text { per father (includes fathers } \\
\text { imprisoned more than once) }\end{array}$ & 2.29 & $(2.05 ; 2.55)$ & 2.74 & $(2.48 ; 3.01)$ & 2.49 & $(2.31 ; 2.67)$ \\
\hline $\begin{array}{l}\text { No. of men in prison first time } \\
\text { with children 2008-09 }\end{array}$ & 1,033 & & 279 & & 1,312 & \\
\hline $\begin{array}{l}\text { No. of children who experienced } \\
\text { paternal imprisonment 2008-09 }\end{array}$ & 2,366 & $(2,118 ; 2,634)$ & 765 & $(692 ; 840)$ & 3,267 & $(3,030 ; 3,503)$ \\
\hline $\begin{array}{l}\text { Total number of children } \\
0 \text {-17 years (between 1991-2008) } \\
\text { who experienced paternal } \\
\text { imprisonment }\end{array}$ & 37,524 & $(33,591 ; 41,774)$ & 11,223 & $(10,152 ; 12,323)$ & 48,748 & $(45,212 ; 52,265)$ \\
\hline $\begin{array}{l}\text { Population of children } \\
0-17 \text { years in } 2008\end{array}$ & 976,901 & & 68,955 & & $1,045,856$ & \\
\hline Percent of children in QLD & $3.84 \%$ & $(3.44 \% ; 4.28 \%)$ & $16.28 \%$ & $(14.72 \% ; 17.95 \%)$ & $4.66 \%$ & $(4.32 \% ; 5.00 \%)$ \\
\hline
\end{tabular}

\section{Discussion}

The purpose of this study was to examine Queensland children's annual and lifetime experiences of paternal imprisonment and by doing this, consider the generalisability of Quilty's (2004) study of parents in NSW prisons. A second aim was to expand what is currently known in Australia about the provision of care of a child prior to, and during, the imprisonment of their father.

We estimated that 0.8 per cent of children in Queensland, aged 17 years or younger, experienced the imprisonment of their father in a one-year period. This corresponds reasonably well with Quilty's (2003) national estimates that 0.5 per cent of children, 15 years or younger, have a father in prison. However, the picture looks very different when Indigenous and non-Indigenous children are examined separately. While 0.5 per cent of non-Indigenous children experienced the imprisonment of their father in a one-year period, our annual figure for Indigenous children was much higher, with 4.4 per cent experiencing the imprisonment of their father. When conducting lifetime estimates, we found that between 3.3 per cent and 3.8 per cent of non-Indigenous children and between 12.5 per cent and 16.3 per cent of Indigenous children were likely to experience paternal imprisonment. This is similar to Quilty and colleagues' (2004: 342) estimates, which included maternal and paternal imprisonment, that 5 per cent of non-Indigenous and 20 per cent of Indigenous children would experience parental imprisonment in their lifetime.

Despite the different methodologies used in the studies, with our study surveying new prisoner intakes over a six-month period and the study by Quilty and colleagues (2004: 340) using randomly selected prisoners at one point in time, the results are reasonably consistent. Furthermore, the studies contained a similar number of fathers and, in the current study, the participants seemed to 
be reasonably representative of the broader prison population (apart from in relation to Indigeneity). Therefore we can be confident in using these estimates to discuss children's experience of paternal imprisonment in the Australian context.

When considering the potential effect of paternal imprisonment on children, of relevance is the finding that just under half of the children reportedly lived with their father prior to his imprisonment. This is a similar figure to that obtained in the United States by Maruschak and colleagues (2010: 41). Among the general Australian population, only around 17 per cent of children aged 0-17 years have their natural father living elsewhere (ABS 2011). This means that even prior to their imprisonment, fathers in our Queensland study were absent from their children's homes at a rate almost three times higher than were fathers in the general Australian population. Whether this is a protective factor or a risk factor for children is unknown. However, recent research has found that increased child aggression in children of imprisoned fathers is stronger if they lived with their father prior to his imprisonment (Geller et al. 2012: 66). Jaffee and colleagues (2003: 116-117) also reported such a relationship, but found that increased childhood aggression was only associated with living with a highly antisocial father. Where the father's antisocial behaviour was low or medium, the longer the child lived with their father, the lower the child's level of aggression. The mechanisms underlying such findings require attention in future research. Nevertheless, the possibility that children who were living with their father prior to his imprisonment are more vulnerable to behavioural problems such as increased aggression deserves attention when considering support and developmental prevention programs for families and parenting programs in prison.

Consideration should also be given to the transitioning of fathers back into the family home, since fathers reported that about 88 per cent of the children who were living with them prior to their imprisonment were expected to live with their father again upon his release. Following pre-release and post-release interviews with imprisoned fathers and their families in the United Kingdom, Lösel and colleagues (2012) found that maintaining quality family relationships through the imprisonment period are important and relate to the positive adjustment and wellbeing of children upon the return of their father. In a study of released prisoners in the United States, Visher and Courtney (2007: 5) found that family members were the most frequently reported reason of men staying out of prison up to twelve months post-release. However, in Australia, Halsey and Harris (2011: 82) have noted that fathers' 'capacity to "do" fatherhood is fundamentally restricted' in prison, leading many men to feel disconnected from their children. Research needs to be conducted to examine how imprisonment affects the maintenance of father-child relationships, whether new risks are posed to the child's development during the post-release period and how these might be mitigated. Research is also needed to explore the challenges posed to the father's rehabilitative efforts on returning, or not returning, to the family home and parental responsibilities. 
In the majority of cases the biological mother was the primary caregiver of the child while the father was in prison and care arrangements were similar regardless of Indigenous status. However, an interesting picture emerged when looking at care arrangements according to whether the child was living with the father prior to his imprisonment. Children were more likely to be living with their biological mother if they had also been living with their father prior to his imprisonment, compared to children who were not living with the father. If they were not living with their father prior to his imprisonment, they were more than three times more likely to be under the care of the child protection system than children who had been living with their father. So caution needs to be taken when considering the effects of imprisonment on children who were living with their father prior to his imprisonment, recognising that children who were not living with their father may have been exposed to additional developmental risks that had led to them being under the care of the State. We cannot assume that just because a child had not been living with their father prior to his imprisonment that they are not vulnerable to family instability and poorer developmental outcomes later in life.

Finally, we examined the quality of accommodation for fathers and the extent of homelessness prior to his imprisonment. This was examined separately according to whether the father had been living with his children. According to Chamberlain and MacKenzie $(1992,2008)$, while it is culturally desired in Australia to be an owner-occupier, the minimum community standard of housing is a small rental flat containing 'a bedroom, living room, kitchen, bathroom and an element of security of tenure' (2008: 3). Homelessness is distinguished at the primary, secondary and tertiary level. Chamberlain and Mackenzie's (2008) estimates derived from the 2006 Census found that 10 per cent of homeless households comprised families with children. In the current study, approximately 16 per cent of fathers fulfilled one of the categories of homelessness, while a further 31 per cent (two per cent in caravan parks and 29 per cent living with friends or relatives in a long-term stay arrangement) could be regarded as inadequately or marginally housed (Chamberlain \& MacKenzie 1992, 2008). We found that the extent of homelessness was far greater if the father was not living with his children (23.5 per cent), with a further 41 per cent being inadequately housed (four per cent in caravan parks and 37 per cent living with friends or relatives in a long-term stay arrangement). Interestingly, 4.3 per cent of fathers who were living with their children prior to imprisonment would be classified as secondary homeless, as they had only temporary shelter with friends or family. This figure was much higher (almost 12 per cent) if the father had not been living with their children.

According to the 2006 Census (ABS 2007), 65 per cent of occupied private dwellings were owned outright or being purchased (mortgage/rent-buy scheme). This statistic is far lower, at 20 per cent, for fathers who were living with their children and an even lower (nine per cent) for fathers who were not living with their children prior to their imprisonment. Clearly many fathers, and in some cases their children, are living at the margins of acceptable housing prior to their imprisonment, while others are experiencing some level of homelessness. Given 
that the imprisonment of a father often results in serious economic consequences for families, consideration needs to be given towards what this means for the subsequent quality of housing of these families and their risk of homelessness.

A significant finding that should not be overlooked in the current study is that Indigenous children are nine times more likely annually, and four times more likely in their lifetime, to experience the imprisonment of their father. A possible reason for the smaller difference in lifetime estimates between Indigenous children and non-Indigenous children is that Indigenous prisoners have higher rates of prior imprisonment ( 74 per cent) than non-Indigenous prisoners (48 per cent; ABS 2012a). Therefore when counting the number of men imprisoned for the first time for the lifetime estimates, there were proportionally fewer Indigenous fathers than non-Indigenous fathers compared to the annual estimates. While children's experiences of repeat paternal imprisonment could not be calculated in the present study, it is likely that, proportionally, more Indigenous children experience the repeat imprisonment of their father.

The potentially devastating effect of paternal imprisonment on up to 16 per cent of our Indigenous youth has never been examined. Kinship within Indigenous communities goes beyond the nuclear family to include recognition of extended and tribal family (Aboriginal Services Directorate 2003). Removal and subjugation by imprisonment of one or more parents or kinship family members, and the removal of Indigenous children into State care continues to erode the security that the traditional Indigenous family once provided (Howard 2001: 3). Relative to non-Indigenous children in Australia, Indigenous children of the same age face a range of developmental and environmental difficulties independent of parental incarceration (Howard 2001), including higher rates of juvenile offending, detention and suicide and lower rates of school completion and employment (Australian Research Alliance for Children and Youth 2013). These independent difficulties make this group particularly vulnerable when faced with the additional stress of parental imprisonment and may increase the risk of intergenerational criminality as well as intergenerational social exclusion and other poor developmental outcomes. According to Dodson and Hunter (2006: 35), there is a need for longitudinal data that 'explicitly examines the developmental processes facing Indigenous children', in order to understand the links between the relationship of criminality and the family environment.

The current study has provided some much needed basic data on the number of Queensland children who experience the imprisonment of their father as well as basic information relating to care and housing. However, caution should be exercised when using these estimates. The data were collected over a six-month period, but extended to create estimates over a 12-month period and 17year period. The extent to which our sample is representative of imprisoned fathers or imprisoned men more generally over these periods is not known. For example, we do not know how many men who declined to participate were also fathers. We assumed that they comprised both those who declined because they had no children under 18 and those who did have children but did not wish to take part in the study. However, if more than about 50 per cent of them 
had children under 18 years, it is possible that we have underestimated the prevalence of children in Queensland with an imprisoned father. Furthermore, these may be fathers who have little contact with their children or where family relationships are more strained. The children may also be at heightened risk of homelessness or at risk of going into State care. As a consequence, the current study is a beginning point only and contains reasonably conservative estimates. In addition, when calculating the estimates an assumption was made that Indigenous children had Indigenous fathers. As this is not always the case, it is possible that we have underestimated the number of Indigenous children with a father in prison. In order to improve the accuracy of parental data, correctional services in every State and Territory should routinely collect this information upon the intake of each prisoner. That such data are not collected is reflective of the low weight and relevance that parenthood is likely given during the detention and rehabilitation of prisoners.

What this study cannot answer is how many of these children require additional support when a parent is imprisoned. It is likely that some children require substantial support while others may need very little. How this relates to whether the child was living with the father prior to his imprisonment is not yet known. As noted by Wildeman (2010) and Giordano (2010), the removal of a parent from the family home may be a protective factor, providing a period of respite for children exposed to highly antisocial or violent behaviour and/or substance abuse. However, there is little research on the potentially protective nature of parental imprisonment and how this balances against other negative consequences of the imprisonment of a parent, such as grief, trauma, poverty and stigma. What kind of resources and support are required for families and when and where should they be directed? We could be better informed in these endeavours by understanding the mechanisms that increase or decrease risk from paternal (and maternal) imprisonment. Longitudinal research internationally is beginning to address these questions, but we need more local research.

The data from the current study reveal that we need to consider the level of pre-existing risk factors in these children, their families and their communities as well as how these change over time as children experience paternal imprisonment, and possibly, the repeat imprisonment of their father. Changes in caregiver status, contact with the child protection system, marginal housing, and separation from the father prior to his imprisonment demonstrate the complexity of these children's lives and that such complexity must be considered when conducting research and developing programs in this field. With approximately four per cent of Queensland children experiencing the imprisonment of their father during their childhood, the possible ramifications for these children's life course should not be ignored. 


\section{Acknowledgements}

This research has been supported by an Australian Research Council Linkage grant (LP0776296), an Australian Research Council Future Fellowship (FT0991557) for the lead author, as well as our partnership organisations, Queensland Corrective Services, Department of Communities, Child Safety and Disability Services, and Catholic Prison Ministry. Views expressed in this paper are those of the authors and do not necessarily represent those of the Australian Research Council or partner organisations. Where quoted or used, they should be clearly attributed to the authors. The authors would like to thank Leah Hodson, the senior research assistant on the project, for her diligence throughout the data collection period. The authors would also like to thank Dr. Michael Townsley for his statistical advice regarding the estimates and Holly Smallbone for her assistance with proofreading the final edits. Importantly, we would like to thank the editors and reviewers for their helpful comments on earlier versions of the paper. Finally, we would like to extend our thanks and appreciation to the many correctional staff involved in the project across the five centres and to the fathers who took part in the study for sharing such valuable, yet personal, information.

\section{References}

Aboriginal Services Directorate (2003) Kinship and culture. Review of Policy Directive 9 Permit for Absence, Aboriginal Services Directorate.

ABS (Australian Bureau of Statistics) (2007) 2006 Census QuickStats: Australia. (2008) Australian Historical Population Statistics, 2008, Cat. No. 3105.0.65.001.

- (2009) Experimental Estimates and Projections, Aboriginal and Torres Strait Islander Australians, 1991 to 2021, Cat. No. 3238.0.

- (2011) Family Characteristics Survey: Summary of Results, 2009-2010, Cat. No. 44420DO013_20092010.

- (2012a) Prisoners in Australia, 2011, Cat. No. 4517.0.

— (2012b) Criminal Courts, Australia, 2010-11, Cat. No. 4513.0.

- (2012c) Census of Population and Housing - Counts of Aboriginal and Torres Strait Islander Australians, Cat. No. 2075.0.

— (2012d) Regional Population Growth, Australia, 2010-11, Cat. No. 3218.0.

Australian Institute of Health and Welfare (2005) A Picture of Australia's Children, Canberra, Australian Institute of Health and Welfare.

Australian Research Alliance for Children and Youth (2013) Report card: the wellbeing of young Australians, Canberra, Australian Research Alliance for Children and Youth. 
Besemer, S., van de Geest, V., Murray, J., Bijleveld, C.C.J.H. \& Farrington, D.P. (2011) 'The relationship between parental imprisonment and offspring offending in England and the Netherlands', British Journal of Criminology, 51 (2), 413-437.

Chamberlain, C. \& MacKenzie, D. (1992) 'Understanding contemporary homelessness: issues of definition and meaning', Australian Journal of Social Issues, 27 (4), 274-297.

Chamberlain, C. \& MacKenzie, D. (2008) Counting the Homeless, Australia, 2006, Canberra, Australian Bureau of Statistics.

Dodson, M. \& Hunter, B. (2006) 'Selected crime and justice issues for Indigenous families', Family Matters, 75, 34-41.

Foster, H. \& Hagan, J. (2007) 'Incarceration and intergenerational social exclusion', Social Problems, 54 (4), 399-433.

Geller, A., Cooper, C.E., Garfinkel, I., Schwartz-Soicher, O. \& Mincy, R.B. (2012) 'Beyond absenteeism: father incarceration and child development', Demography, 49 (1), 49-76.

Geller, A., Garfinkel, I., Cooper, C.E. \& Mincy, R.B. (2009) 'Parental incarceration and child well-being: implications for urban families', Social Sciences Quarterly, 90 (5), 1186-1202.

Giordana, P. C. (2010) Legacies of Crime: A Follow-Up of the Children of Highly Delinquent Girls and Boys, New York, Cambridge University Press.

Glaze, L.E. \& Maruschak, L.M. (2008) Parents in Prison and Their Minor Children, NCJ 222984, Washington, D.C: U.S. Department of Justice, Bureau of Justice Statistics http://www.bjs.gov/content/pub/pdf/pptmc.pdf

Halsey, M. \& Harris, V. (2011) 'Prisoner futures: sensing the signs of generativity', Australian and New Zealand Journal of Criminology, 44 (1), 74-93.

Howard, S. (2001) 'Fathering and Indigenous families: a North Queensland community partnership', paper presented to the Helping Families Change Conference, Melbourne, 22-24 February.

Jaffee, S.R., Moffitt, T.E., Caspi, A. \& Taylor, A. (2003) 'Life with (or without) father: the benefits of living with two biological parents depend on the father's antisocial behavior', Child Development, 74 (1), 109-126.

Johnston, D. (1995) 'Effects of parental incarceration'. In K. Gabel \& D. Johnston (eds) Children of Incarcerated Parents, New York, Lexington Books.

Kinner, S.A., Alati, R., Najman, J.M. \& Williams, G.M. (2007) 'Do paternal arrest and imprisonment lead to child behaviour problems and substance use? A longitudinal analysis', Journal of Child Psychology and Psychiatry, 48 (11), 1148-1156.

Lösel, F., Pugh. G., Markson, L., Souza, K. \& Lanskey, C. (2012) Risk and protective factors in the resettlement of imprisoned fathers with their families: final report, University of Cambridge. 
Maruschak, L.M., Glaze, L.E. \& Mumola, C.J. (2010) 'Incarcerated parents and their children: findings from the Bureau of Justice Statistics'. In J. M. Eddy \& J. Poehlmann (eds) Children of Incarcerated Parents: A Handbook for Researchers and Practitioners, Washington, D.C., The Urban Institute Press.

Murray, J. \& Farrington, D. P. (2005) 'Parental imprisonment: effects on boys' antisocial behaviour and delinquency through the life-course', Journal of Child Psychology and Psychiatry, 46 (12), 1269-1278.

Murray, J. \& Farrington, D. P. (2008) 'Parental imprisonment: long-lasting effects on boys' internalizing problems through the life course', Development and Psychopathology, 20 (1), 273-290.

Murray, J. (2010) 'Longitudinal research on the effects of parental incarceration on children'. In J. M. Eddy \& J. Poehlmann (eds) Children of Incarcerated Parents: A Handbook for Researchers and Practioners, Washington, D.C., The Urban Institute Press.

Murray, J., Farrington, D. P. \& Sekol, I. (2012) 'Children's antisocial behaviour, mental health, drug use, and educational performance after parental incarceration: a systematic review and meta-analysis', Psychological Bulletin, 138 (2), 175-210.

Quilty, S. (2003) The health of the families and children of prisoners. MPhil Thesis, The University of Sydney, Australia (unpublished).

Quilty, S., Levy, M., Howard, K., Barratt, A. \& Butler, T. (2004) 'Children of prisoners: a growing public health problem', Australian and New Zealand Journal of Public Health, 28 (4), 339-343.

Sampson, R. J. (2011) 'The incarceration ledger: toward a new era in assessing societal consequences', Criminology and Public Policy, 10 (3), 819-828.

Schwartz-Soicher, O., Geller, A. \& Garfinkel, I. (2011) 'The effect of paternal incarceration on material hardship', Social Service Review, 85 (3), 447473.

Ulm, K. (1990) 'Simple method to calculate the confidence interval of a standardized mortality ratio (SMR)', American Journal of Epidemiology, 131 (2), 373-375.

Visher, C. A. \& Courtney, S.M.E. (2007) One year out: Experiences of prisoners returning to Cleveland, Returning Home Policy Brief, Washington, DC, Urban Institute Policy Center.

Walker, J. \& McCarthy, P. (2005) 'Parents in prison: the impact on children'. In G. Preston (ed.) At Greatest Risk: The Children Most Likely to be Poor,London, Child Poverty Action Group.

Wildeman, C. (2010) 'Paternal incarceration and children's physically aggressive behaviors: evidence from the Fragile Families and Child Well-being Study', Social Forces, 89 (1), 285-309. 


\section{Endnotes}

1. A chi-square test only determines whether a significant difference exists between expected and observed frequencies across groups. As there were four groups for marital status, the post hoc analysis using the reasonably conservative Tukey B test allowed a comparison between each 2-way combination of groups without increasing the likelihood of making a Type 1 error (that is, finding a significant difference where none exists).

2. The method of calculating the lifetime estimates is reasonably conservative. However, a simplified alternative method of taking the 12-month estimate of the percentage of children who experience paternal imprisonment and multiplying it by 18 would potentially inflate the estimates. An examination of this alternative method revealed estimates above the reported confidence intervals of the more conservative method. 
Copyright of Australian Journal of Social Issues (Australian Social Policy Association) is the property of Australian Social Policy Association and its content may not be copied or emailed to multiple sites or posted to a listserv without the copyright holder's express written

permission. However, users may print, download, or email articles for individual use. 